\title{
Estimate of Chinese Core Inflation Rate--The Application of Space State Model Based on Time--Varying Parameter
}

\author{
Jiang-Long SHAO \\ The School of Economics of Shanghai University \\ smallon@qq.com
}

Key words: core inflation rate kalman filtering output gap positive analysis

\begin{abstract}
The paper based on the theory of new Keynesian and phillips curve, that is regarding the anticipated inflation in the additional and anticipated phillips curve equation as the core inflation. To formulate variable parameters model through space state model, to estimate the core inflation rate from January 1996 to December 2015 in China by kalman filtering and to test the estimated results. The results show that the estimated volatility is smaller and having more strong theoretical foundation and meet the realistic condition in our country's economic transition period and has guiding significance for policy making.
\end{abstract}

\section{Introduction}

As the economic growth continues to slow in recent years, the central bank began to start the continuous monetary easing policy, Since Nov. $22^{\text {th }} 2014$, reduced the financial institutions RMB loan and deposit rates for the first time and opened a new round of interest rates and deposit reserve reducing channel, has accumulated to reducing five times and four times until December 2015, the recent CPI continues to fall and the economic downward pressure increases, our country is facing the risk of inflation austerity. In order to judge the current economic situation and to formulate reasonable macroeconomic policies, we need to take in-depth understanding and analysis for the CPI index and to distinguish the fluctuation composition and trend composition in the CPI changes and the latter is often been called as the core inflation rate in the literature.

The core inflation as a term that was put forward by Otto Eckstein in 1981, he thinks that the core inflation rate is the inflation rate when the market is in the long -term equilibrium state. Later many scholars defining the concept of core inflation, although the words expression are not completely consistent, but all think that the core inflation is the long-term component of inflation after stripping out short time factor and reflect the long-term trend of price changes, it is a focus attention object of monetary policy.

The estimated methods of current core inflation can be roughly divided into statistical method and measurement method. The different methods have different pros and cons. The statistical method is simply operated and easy to understand by general public but lacking economic theory foundation with strong subjectivity. But the measurement method considers information fully and the prediction effect is good with good theoretical support but exists the defects of complicated calculation and bad real-time characters

\section{The Literature Review}

Over the past twenty years, the domestic and foreign scholars have done a lot of research about core inflation. Quah and Vahey (in 1995) through SVAR model to impose the long-term constraint based on the economic theory, taking the observed inflation as the core inflation and non-core inflation; Bryan and Cecchetti (in 1993, 1997) estimated the core inflation according to the dynamic factor index model, Stock and Waston (in 1999) used the common trend model to measure the core inflation; Bryan and Cecchetti (in 1999) used the methods of trimming averaging and weighted median to estimate the monthly core inflation of Japan. Anderson et al. (in 2007), Down et al (in 2010) and Baqaee (in 2010) used the wavelet method to estimate the core inflation of American and New Zealand 
Our country's economy scholars researching the core inflation basically used the foreign academic research methods to analyze the core inflation in China. Liuyan Zhao used the new phillips curve to set the non-observation component models including inflation and output and to estimate Chinese core inflation rate and output gaps. Xudong Zhao(in 2008) extended the two variable structures of Quah and Vahey into vector autoregressive (SVAR) model, established the three variables SVAR models including the consumer price index, food price index and output. Dan Tang and Xindong Zhao (in 2011) established the state space models to estimate the core inflation then used the Gibbs Sampler's methods in the parameters to estimate the space models in order to overcome the defects of kalman filtering. Zhiyong Cheng, Jingxun Wu (2013) fully considered the relationship between variables based on the estimation methods of kalman filtering and multiple HP filter core inflation rate, which is better than the trend stationarity based on the general statistical methods

This paper referred the research achievements about core inflation rate estimates in the domestic and abroad literature with the aid of the state space model of time-varying coefficients and estimated our country's core inflation by using kalman filtering. Compared with other statistical approach, the volatility is smaller, the trend is more stable and can provide a certain of references.

\section{Empirical Results and Analysis}

Due to the impact of economic reform, external shocks and policy changes, China's economic structure is undergoing great changes in recent years. The inflation which is the core of this paper is the result of a variety of economic variables. And the state space model can be used to estimate the multivariate time series model, based on which we can construct the variable parameter model.

\section{The Establishment of State Space Model}

Based on the theory of new Phillips Keynes curve, this paper took advantage of the state space model to construct the variable parameter model and the Kalman filtering to estimate the core inflation. In this theory, the anticipated inflation in the expectations-augmented Phillips Curve was regarded as the core inflation, that is, the output is in the potential level without supply shock.

Let $\pi_{t}$ represent the real inflation rate, $\pi_{t}^{c}$ represent the core inflation rate, $y_{t}^{\text {tram }}$ represent the output gap, $X_{t}$ represent vector quantity constituted by a variety of real and nominal shocks and $\varepsilon_{t}$ represent independent identical distribution sequence that subjects to $\mathrm{N}\left(0, \delta_{1}^{2}\right)$, and then the key equation of the model is:

$$
\pi_{\mathrm{t}}=\pi_{\mathrm{t}}^{\mathrm{c}}+\alpha \mathrm{y}_{\mathrm{t}}^{\mathrm{tran}}+\beta_{\mathrm{t}} \mathrm{X}_{\mathrm{t}}+\varepsilon_{\mathrm{t}} \quad \mathrm{a}
$$

If you set the new Phillips Keynes Curve in another way, you can deduce the evolvement rule of the core inflation along with time. The Phillips equation can be expressed as:

$$
\pi_{t}=E_{t} \pi_{t+1}+\gamma y_{t}^{\text {tran }}+\varepsilon_{t}
$$

Et is the expectation operator of the future inflation rate based on the obtained information from the t period. When there is no supply shocks, and the real output equals potential output, the output gap $y_{t}^{\text {tran }}=\varepsilon_{t}=0$, and the equilibrium rate of inflation $\pi_{t}^{*}=E_{t} \pi_{t+1}$, Since inflation is a monetary phenomenon, the long-term component of inflation rate can only be caused by monetary policy, and the pressure on inflation caused by supply shocks and output gap can only lead to short-term fluctuations in the price, which are not regarded as the core inflation rate changes. So we can directly define the expected value of the future inflation on the right side of equation "b" as core inflation. In this way, the core inflation rate can be understood as the long-term inflation rate corresponding to zero output gap. We can define the evolution process of the core inflation rate as follows: the random walk process:

$$
\pi_{t}^{c}=\pi_{t-1}^{c}+v_{t}, v_{t} \text { is IID sequence that subjects to } \mathrm{N}\left(0, \delta_{2}^{2}\right)
$$

In this way, "a" is the measurement equation of state space model, while "c" is the state equation of state space model. 


\section{Selection and Processing of Model Variables}

Explanatory variable vector contains a variety of variables affecting inflation. According to the real inflation changes in the past ten years, variables in this paper all impact on the trend of inflation in various degrees, including: selecting monetary base supply "M0" and state foreign exchange reserves "EXR" as nominal shocks to inflation; selecting the short-term nominal interest rate "I", international crude oil prices "OIL", indirect tax "T" and labor productivity "LDSCL" as actual shocks to inflation; and selecting the output gap as short-term shocks to inflation.

Sample period: January 1996 - December 2015, monthly data. The consumer price index CPI came from the website of the National Bureau of statistics, which was converted to fixed base CPI index taking January 1996 as the base; Monetary base supply "M0", foreign exchange reserves "EXR" and short-term interest rate "i" came from the official website of the central bank; The international crude oil price came from the WTI data and was converted into RMB price through the current exchange rate; and the indirect tax "TAX" referred the whole government revenue minus personal income tax and tariff. Labor productivity is the ratio of total industrial production "IP" and the number of employees "EM", among which "IP", "EM" and the exchange rate "E" are all derived from the wind database. On the one hand, the seasonal adjustment is carried out on the above variable data in order to overcome the seasonal fluctuation; on the other hand, it can ensure the stability of time series by the logarithm difference of the sequence.

For the output gap, since there is no monthly value of GDP, we used monthly industrial production "IP" to take the place of GDP. Based on the logarithm of the total industrial production $\mathrm{IP}=\ln (\mathrm{IP})$, the real output is decomposed into trend component and period component by HP filter, among which trend components is the potential output while the cycle components is the output gap.

\section{Model Estimation and Empirical Results}

In order to ensure the stability of time series and prevent spurious regression, the unit root test is needed by the time sequence data before model estimation. The treated results of various variables unit root test are shown in table 1:

Table 1 Unit root test

\begin{tabular}{c|c|c|c|c|c|c}
\hline Variable name & Symbol & $\mathrm{t}-$ Statistic & $1 \%$ level & $5 \%$ level & $10 \%$ level & Prob. \\
\hline real inflation rate & $\mathrm{dcpi}$ & -12.5309 & -3.4577 & -2.8735 & -2.5732 & 0.0000 \\
\hline $\begin{array}{c}\text { The growth rate of the } \\
\text { base currency }\end{array}$ & $\mathrm{dm} 0$ & -2.8828 & -3.4590 & -2.8740 & -2.5735 & 0.0489 \\
\hline $\begin{array}{c}\text { Foreign exchange reserve } \\
\text { rate of change }\end{array}$ & $\mathrm{dexr}$ & -2.7163 & -3.4581 & -2.8736 & -2.5733 & 0.0727 \\
\hline $\begin{array}{c}\text { Short-term interest rate } \\
\text { of change }\end{array}$ & $\mathrm{di}$ & -18.1745 & -3.4577 & -2.8735 & -2.5732 & 0.0000 \\
\hline $\begin{array}{c}\text { Crude oil price rate } \\
\text { of change }\end{array}$ & $\mathrm{doil}$ & -11.7627 & -3.4577 & -2.8735 & -2.5732 & 0.0000 \\
\hline $\begin{array}{c}\text { Indirect tax rate } \\
\text { of change }\end{array}$ & $\mathrm{dtax}$ & -10.3167 & -3.4590 & -2.8740 & -2.5735 & 0.0000 \\
\hline $\begin{array}{c}\text { Change of } \\
\text { labor productivity }\end{array}$ & $\mathrm{dldscl}$ & -15.4205 & -3.4577 & -2.8735 & -2.5732 & 0.0000 \\
\hline Output gap & $\mathrm{ytran}$ & -5.4098 & -3.4591 & -2.8741 & -2.5735 & 0.0000 \\
\hline
\end{tabular}

From table 1 we can see: among the treated variables, except the growth rate of base currency and foreign exchange reserves rate of change rejected the null hypothesis of unit root in the critical level at the rate of $10 \%$, other variables highly rejected the null hypothesis of unit root in the critical 
level at the rate of $1 \%$ in the state of stationary series. The results of unit root test show that the processed variables are all first-order single integer sequence. In order to avoid spurious regression, this paper carries out co integration test on eight variables. The results are as follows:

Table 2 Cointegration test of variables

\begin{tabular}{c|c|c|c|c|c}
\hline \multirow{2}{*}{$\begin{array}{c}\text { Hypothesized } \\
\text { No. of CE(s) }\end{array}$} & \multirow{2}{*}{ Eigenvalue } & \multicolumn{2}{|c|}{ Trace test } & \multicolumn{2}{c}{ Max-eigenvalue test } \\
\cline { 3 - 5 } & & Trace Statistic & Prob. & Max-Eigen Statistic & Prob \\
\hline None* $^{*}$ & 0.377356 & 443.6906 & 0.0000 & 110.8647 & 0.0000 \\
\hline At most 1* & 0.327257 & 332.8260 & 0.0000 & 92.75582 & 0.0000 \\
\hline At most 2* & 0.271191 & 240.0701 & 0.0000 & 74.02433 & 0.0000 \\
\hline At most 3* & 0.236390 & 166.0458 & 0.0000 & 63.10940 & 0.0000 \\
\hline At most4* & 0.182514 & 102.9364 & 0.0000 & 47.15600 & 0.0001 \\
\hline At most5* & 0.108851 & 55.78041 & 0.0000 & 26.96703 & 0.0067 \\
\hline At most6* & 0.096762 & 28.81338 & 0.0000 & 23.81387 & 0.0012 \\
\hline At most 7* & 0.021139 & 4.999511 & 0.0253 & 4.999511 & 0.0253 \\
\hline
\end{tabular}

Table 2 shows that under the significant level of 5\%, whether the trace test or Max-eigenvalue test all reject the null hypothesis of cointegrated vector, indicates the cointegration relation between variables, and could be further analyzed by establishing corresponding models.

This paper sets up the state space model by Eviews software, the state space form is expressed as follows;

Measurement equation:

dcip $=\mathrm{c}(1)+\mathrm{svl}{ }^{*} \mathrm{ytran}+\mathrm{sv} 2 * \mathrm{dm} 0+\mathrm{sv} 3 * \mathrm{dexr}+\mathrm{sv} 4 * \mathrm{di}+\mathrm{sv} 5 *$ dtax $+\mathrm{sv} 6 *$ doil $+\mathrm{sv} 7 *$ dldscl +

$[\operatorname{var}=\exp (c(2))]$

State equation:

$$
\begin{array}{llll}
\text { @state sv1 = sv1(-1) @state sv2 = sv2(-1) @ @state sv3 = sv3(-1) @ @state sv4 = sv4(-1) } \\
& \text { @state sv5 = sv5(-1) @ @state sv6=sv6(-1) @ @state sv7 = sv7(-1) }
\end{array}
$$

After the model is generated, the estimated values of the parameters are set up by using the kalman filtering. Then starting with the initial value and variance of the state variable, by the three algorithms of filtering, smoothing and prediction to infer the state variables of non-observable. Estimated parameter result list as follows:

Table 3 Result of parameter estimation

\begin{tabular}{c|c|c|c|c|c|c|c|c|c}
\hline & sv1 & sv2 & sv3 & sv4 & sv5 & sv6 & sv7 & $\mathbf{C ( 1 )}$ & $\mathbf{C ( 2 )}$ \\
\hline $\begin{array}{c}\text { Estimated } \\
\text { value }\end{array}$ & 0.27 & 0.01 & 0.02 & 0.08 & 0.00 & 0.01 & 0.00 & 0.16 & -1.81 \\
\hline $\begin{array}{c}\text { Standard } \\
\text { deviation }\end{array}$ & $(0.47)$ & $(0.01)$ & $(0.01)$ & $(0.05)$ & $(0.00)$ & $(0.00)$ & $(0.01)$ & $(0.05)$ & $(0.06)$ \\
\hline
\end{tabular}

Log likelihood $=-196.44$

Based on the estimated results, the value of sv1 and sv4 is larger compared with other parameter values, that is to say, the main factors that influence the fluctuation of the inflation rate are the output gap and the short-term interest rate. When the Output gap deviates a percentage point of the potential output, the inflation rate will increase by 0.27 percentage points, The Product gap indicates the gap between actual output and potential output, reflects the utilization of existing economic resources. In many countries, the product area is considered as an important indicator of inflation pressure. The results also show that one percentage point reduced by short-term interest rates, would increase 0.08 percentage points of inflation rate, which indicates the changes in short-term interest rates also significantly impact the rate of inflation. In addition, the long-term trade surplus of our country makes the foreign exchange reserves on continues rising and leads to 
passive delivery of currency, so the foreign exchange reserves also have a significant impact on the high inflation rate. The change of international crude oil price has little effect on China's inflation, which means that China Development and Reform Commission has made some achievement on the control of refined oil price.

After parameter estimation, estimate the core inflation rate in China by using kalman filtering, and draw it with the real inflation rate on one chart, it can be seen through figure 2 that the fluctuation range of the core inflation rate is obviously smaller than the actual inflation rate.

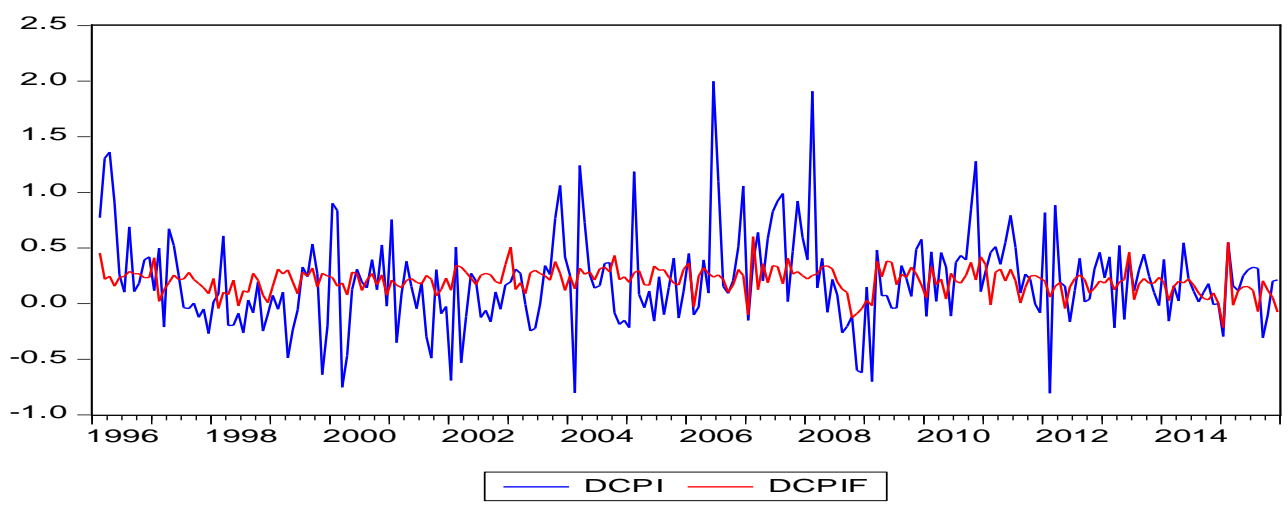

Figure1. Comparison of Core Inflation Rate and Real inflation rate

\section{Empirical Result Analysis}

The core inflation rate must be able to reflect the long-term trend of the change in the rate of inflation, and forecast the future inflation rate. The excluded short-term price section should not cover the useful information for predicting future inflation rates, only such kind of core inflation rate can be a guide to the designation of monetary policy. The following criteria are to test the estimation results based on the time-varying parameter state space model.

\section{Comparison of Stability}

In order to reflect the long term trend of inflation, the core inflation rate is not supposed to have a lot of volatility. In order to show the trend stability of the core inflation rate, respectively calculate the actual inflation rate, the exponential smoothing of the core inflation rate and the kalman filtering estimated core inflation rate, and compare the volatility of the three by graphic and descriptive statistics. There into, DCPISM refers to the core inflation rate after exponential smoothing, DCPI and DCPIF relatively indicates the actual inflation rate and inflation rate estimated by models, volatility is equal to ratio of standard deviation and mean value.

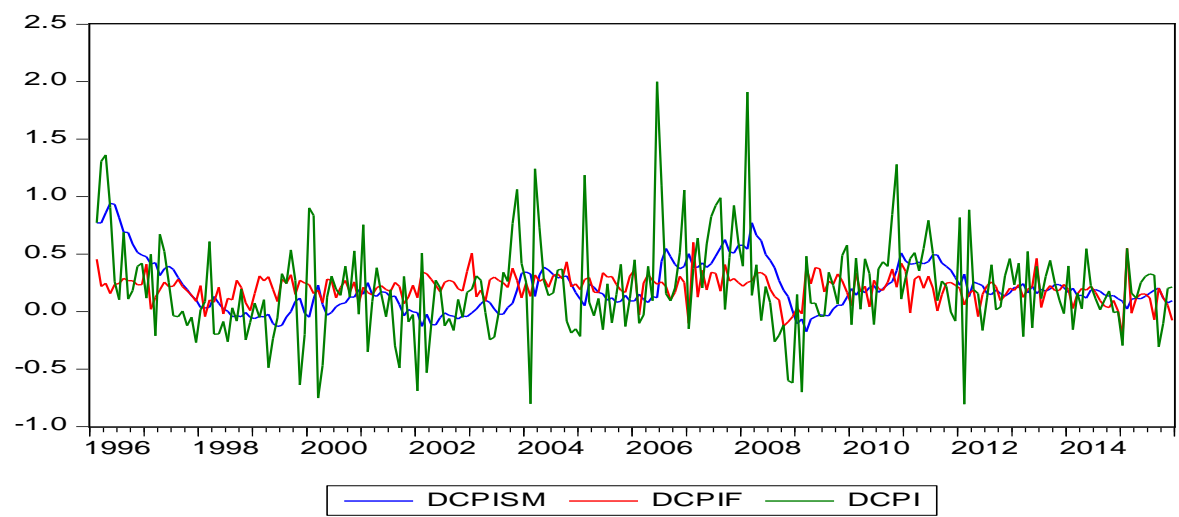

Figure2. Between real inflation Rate and Two Kinds of Core Inflation Rate

Figure 2 has intuitively reflected the fluctuation amplitude of three index, there into, the core inflation rate fluctuation amplitude from kalman filtering is the minimum. Then using descriptive 
statistics method to calculate the volatility of inflation rate. (Volatility =Standard Deviation/Mean Value)

Table 4 The Comparison of Volatility

\begin{tabular}{c|c|c|c}
\hline & Mean Value & Standard Deviation & Volatility \\
\hline real inflation & 0.204 & 0.415 & 1.38 \\
\hline $\begin{array}{c}\text { The Exponential Smooth Core } \\
\text { Inflation }\end{array}$ & 0.205 & 0.214 & 1.04 \\
\hline $\begin{array}{c}\text { The Model Estimated Core } \\
\text { Inflation }\end{array}$ & 0.204 & 0.117 & 0.57 \\
\hline
\end{tabular}

Through the analyses of diagram 4, showing the volatility of estimation of Kalman Filtering is the most small with only 0.57 and the standard deviation is 0.117 , the standard deviation of core Inflation rate was degraded $71.8 \%$ by the article, the estimated core inflation rate excluded the factor of short-term fluctuation and keep stability and to reflect trend factors in real inflation.

\section{Predictability}

For checking the predictability of core inflation rate, At first, carrying out an model selection between the real inflation and core inflation rate by time series, then estimated the two models by maximum likelihood estimate, making one step forecast with In-Sample and Out of Sample . By calculation of the squared error of prediction and analysis of mean value and standard deviation then got the samples' predictability effects. By forecasting 12 months inflation rate of Out of Sample and concluding the mean value and standard deviation between real inflation sequence and core inflation sequence, then analyzing the volatility of two groups of samples and got the Out of Sample' forecast effects.

The diagram 5 showing as below: the sample's mean value of core inflation of the squared error of prediction is 0.049,but the mean value of real inflation of the squared error of prediction is 0.194,that showing sample's mean value of core inflation of squared error is smaller than real inflation's, and the standard deviation is more smaller. When comparison of the effects of non-samples, the forecasting real inflation fluctuation ratio is 0.424 and the core inflation fluctuation ratio is 0.123 ,that less than one-third. No matter how the In-Sample Forecast or Out of Sample Forecast, the core inflation rate has a better refection of the trend inflation and a better forecast ability and more instructive.

Table 5 The Forecast Comparison between Real inflation and Core Inflation

\begin{tabular}{c|c|c|c|c|c}
\hline Name of statistics & \multicolumn{2}{|c|}{ In-Sample Forecast } & \multicolumn{3}{c}{ Out of Sample Forecast } \\
\hline Inflation Rate & $\begin{array}{c}\text { Mean Value of squared } \\
\text { error of prediction }\end{array}$ & $\begin{array}{c}\text { Standard Deviation of } \\
\text { squared error of } \\
\text { prediction }\end{array}$ & $\begin{array}{c}\text { Mean } \\
\text { value }\end{array}$ & $\begin{array}{c}\text { Standard } \\
\text { Deviation }\end{array}$ & $\begin{array}{c}\text { Fluctuation } \\
\text { Ratio }\end{array}$ \\
\hline $\begin{array}{c}\text { Real inflation } \\
\text { rate }\end{array}$ & 0.194 & 0.431 & 0.198 & 0.084 & 0.424 \\
\hline $\begin{array}{c}\text { Core Inflation } \\
\text { Rate }\end{array}$ & 0.049 & 0.050 & 0.065 & 0.008 & 0.123 \\
\hline
\end{tabular}

\section{Rationality}

To prove the price fluctuation ratio was excluded is reasonable, we analyze the BODONG's characters of time series between real inflation rate and Kalman filtering estimated core inflation. From diagram 3, knowing the excluded part of price fluctuation time series is reasonable. 


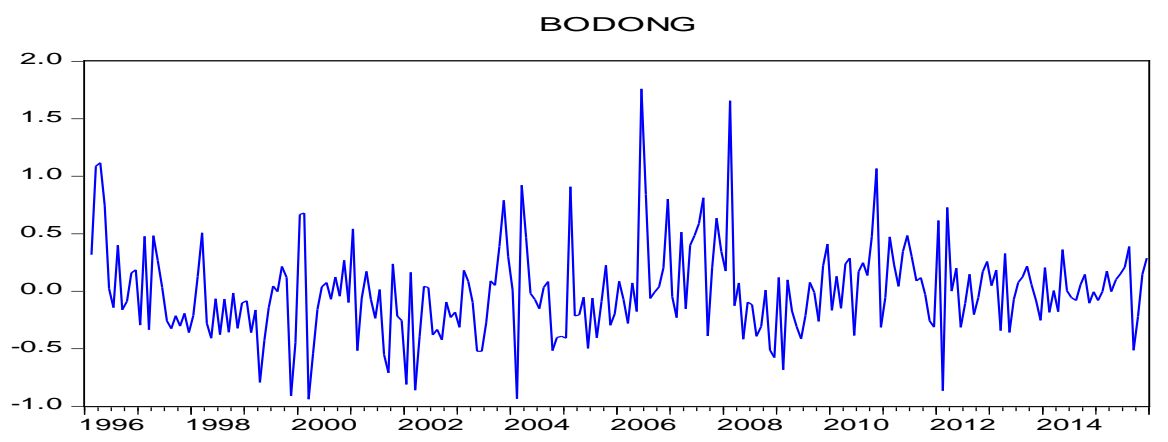

Diagram 3 The Difference between Real inflation and Core Inflation

Through the Diagram 6's ADF test result showing t-Statistic is more less than critical value of $1 \%$, The sequence of BODONG reject null hypothesis at the significance level of $1 \%$ have proved the excepted data in stable process.

Table 6 ADF Test

\begin{tabular}{c|c|c|c|c|c}
\hline & t-Statistic & Prob. & $1 \%$ level & $5 \%$ level & $10 \%$ level \\
\hline BODONG & -13.0339 & 0.0000 & -3.4577 & -2.8735 & -2.5732 \\
\hline
\end{tabular}

Also, the relatively diagram from the BODONG sequence's 40 rank is totally random process of consist of non-relatively sequence of variables, the sequence is non-relatively when all relative sequences in confidence interval. The core inflation's excluded sector not including the information of future inflation variables will not influence long-term trends, so it is reasonable to exclude factor from core inflation.

\section{Conclusion}

The article is basis on the basic theory of the Phillips curve of neo-keynesian, looking the predication of inflation as core inflation with none output gaps and none supplies. The model to estimate core inflation have fully considered the connection between economic variables and laid a good foundation and reflecting the inflation's concept during the period of Long-run equilibrium, the method was based on state space model is adaptive to Chinese conditions, there is a complex condition in inflation mechanism. Generally speaking, the usual statistical method will not reflect the complex economic variables. And the measure model is basis on sufficient information with superior predictably ability can supply the advice and reference for policy-makers.

\section{Reference:}

1. Zhao liuyan The analysis of Chinese core inflation and output's gap, The Economic July,2016

2. Zhao xiudong The estimation and application of basis on SVAR model of Chinese core inflation, The study of statistics the seventh journal,2008

3. Tang dang,Zhao xiudong The estimation of Chinese core inflation-basis on state place model of Gibbs sampler, Economic comments the fif journal,2011

4. Chen yong zhi, Wu jingshun The core inflation estimation of basis on Kalman filtering, Shanhai finance.2013.2 